urinary elimination after the ingestion of marker doses of isoniazid do not vary greatly from individual to individual. ${ }^{1}$

We have recently extended our initial studies by determining the length of time during which positive urine samples were obtained after the ingestion of $6 \mathrm{mg}$ doses of isoniazid by healthy volunteers. Of the 326 urine samples collected from one to 17.5 hours 323 gave reliably positive results in contrast to none of the 246 samples collected before treatment or from 47.5 hours onwards; the proportion of false positive results was less than $1 \%$. Thus; if tablets or capsules containing such isoniazid doses were taken first thing each morning all urine samples collected during the day should give reliably positive results. A negative urine test result would therefore unequivocally indicate a patient's failure to have taken a dose that day. On the other hand while a positive result would not necessarily indicate that a dose had been taken earlier in the day it would conclusively show that one had been ingested during the previous 48 hours.

In addition to these suitable pharmacokinetic properties worldwide experience during the past two decades in the treatment of millions of patients with tuberculosis testifies to the safety of isoniazid when given for periods of at least a year at daily doses of about $300 \mathrm{mg}^{3}$ Furthermore, extensive studies in Britain and the USA have provided no evidence of a carcinogenic effect of such treatment. ${ }^{45}$ There is, therefore, good reason to believe that marker doses of a fiftieth of this amount will bẹ innocuous.

G A ElLARD

P J JENNER

National Institute for Medical Research,

London NW7 1AA

B W ALLEN

Medical Research Council Unit for Laboratory Studies of Tuberculosis,

Department of Bacteriology,

Royal Postgraduate Medical School,

London W12 OHS

${ }^{1}$ Ellard GA, Jenner PJ, Downs PA. Br f Clin Pharmacol 1980;10:369-81.

2 Ellard GA, Greenfield C. F Clin Path 1977;30:84-7.

Girling DJ. Tubercle 1978;59:13-32.

Stott H, Peto J, Stephens R, et al. Tubercle 1976; 57:1-15.

Glassroth JL, White MC, Snider DE. Am Rev Resp
Dis 1977;116:1065-74.

\section{Changing the method of selection at}

\section{Northwick Park}

SIR,-Congratulations are due to the organisers of the vocational training scheme in Northwick Park for trying to find more objective methods for selecting trainees (19 October, p 1087). This is most important in view of the increased demand for training places and the possible effect of selection on the applicant's professional future.

I must take issue with the authors, however, in respect of extraversion and its relevance to the work of the general practitioner. Extraversion, like any other personality trait, is likely to affect interaction between people. The effect, however, is not necessarily number dependent. Thus it seems nonsensical to suggest that the one to one consultation will have better results if the doctor has an introverted rather than an extraverted personality. Besides, during both the vocational training and the professional life of a general practitioner the trend is for an increase in functions requiring group interactions. Although results vary somewhat in accordance with the personality test used, research shows significant correlations between extraversion and preference for many aspects of the general practitioner's role including that of continuing care $^{12}$; introversion on the other hand correlates only with preference for psychological knowledge and research. Important as these two are they cannot be considered to be either the sole or the most important aspects of a general practitioner's job.

\section{SUSIE M K BARRY}

Egham

Surrey T20 0JZ

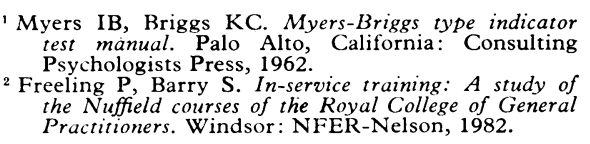

\section{Serological tests for syphilis}

SIR,-As Dr S D Oriel (18 September, p 759) has pointed out the problem of interpretation of positive serological tests for syphilis is difficult in areas where endemic treponematoses are prevalant. The finding of a positive serological test in a blood donor is frequent in such areas. Among blood donors in Martinique we usually find that $3 \cdot 4{ }^{\circ}$ give a positive reagin test (Kline's test) and $2.8^{\circ} \%$ give a positive specific test (Treponema pallidum haemagglutination test). This is in considerable contrast to frequencies found in Europe $(0.04 \%$ give a positive specific test in France). ${ }^{1}$ The serological pattern is not identical with that observed in patients with latent or late syphilis; clinical examination fails to show any evidence of syphilis or yaws. Endemic treponematosis disappeared from Martinique around $1940-5,2$ but early cases have been found in the island since 1977. No satisfactory diagnosis can be made in these donors, and this raises two problems. The first, which has been discussed elsewhere, ${ }^{3}$ is whether or not these people should be treated. The second is common to the Caribbean blood banks where similar frequencies are found ${ }^{1}$ : can this blood be used for transfusion? The survival of $T$ pallidum in blood kept at $4 . \mathrm{C}$ appears to be less than five days ${ }^{4}$ and in frozen plasma 48 hours ${ }^{5}$; the survival of $T$ pertenue has never been studied.

J F MORNEX N MONPLAISIR

Centre départemental de transfusion sanguine de la Martinique,

Fort de France,

${ }^{1}$ Mornex JF, Monplaisir N. Transfusion 1981;21:230. Hopkins DR. F Infect Dis 1977;136:548-54.

3 Anonymous. Br Med $\mathcal{F} 1979 ; \mathrm{i}: 912$

Turner TB, Diseker TH. Bulletin of the fohns Hopkin Hospital 1941;63:269-79. Ravitch MM, Chambers JW. Bulletin of the fohns
Hopkins Hospital 1942;71:299-303.

\section{Campylobacter enteritis and erythema nodosum}

SIR,-I was interested to read the letter from Dr C J Eastmond and Dr T M S Reid confirming the association of erythema nodosum with campylobacter infection (13 November, p 1421). In a large school outbreak of campylobacter enteritis I saw no cases of erythema nodosum but an unusually large number of cases of urticaria.

In this boarding school for 780 boys aged between 10 and 18 years an outbreak of enteritis began on 15 March this year and continued for a week. In a questionnaire completed afterwards by the whole school over half the boys reported some symptoms. One hundred and four had been admitted to the school infirmary, and Campylobacter jejuni was isolated from 35 of the 40 stool specimens examined. Twelve boys, not all of whom had been ill with enteritis, presented with urticaria between 19 and 24 March. In most of them it was mild and transient, but the number of cases was remarkable as the average number of new cases of urticaria observed over the previous decade was only three a year.

T W Hoskins

The Infirmary,

Christ's Horsham,

West Sussex RH13 7LT

\section{Future of cottage hospitals}

SIR,-Few would dispute that the National Health Service is going through a time of crisis. Daily we read of cut backs, health workers' demonstrations, walk outs, and rising medical unemployment. As three general practitioners working in rural communities it might seem strange that a voice of protest should come from such a quarter. The threatened closure of three general practitioner hospitals within Tayside region, however, is a fundamental reflection of the problems facing the Health Service at this time.

The three hospitals threatened are Auchterarder, Crieff, and Meigle cottage hospitals, and they are to be closed as part of Tayside Health Board's policy to save about $£ 2 \cdot 1 \mathrm{~m}$ in the coming financial year. If closure of these hospitals took place and the total running costs of all three were a direct saving the sum would not exceed $£ 628000$. Seventy per cent of our hospital running costs, however, are staff costs, and as no policy of compulsory redundancy is as yet practised by Tayside Health Board all staff would have to be offered employment elsewhere. There would, therefore, be no real saving to the board on at least $70 \%$ of current costs.

The three hospitals admit over 500 patients a year and are responsible for dealing with about 9000 cases a year in the casualty and outpatient departments as well as providing other services such as physiotherapy and chiropody. It is clear that these patients will continue to require medical care. Attendance at larger hospital units many miles away and increased ambulance costs may very well offset any immediate savings and may result in extra expenditure to the board in the years ahead.

We are concerned that our cottage hospitals, which are cost effective small units, are being sacrificed at the expense of larger central hospitals, which seem to be protected from the fiscal constraints applied elsewhere. We would press our administrators to consider that the demands for funds which our large hospitals are placing on limited resources spell disaster for the future of small, efficient, and convenient periphera! units, which in their own communities are just as important, if not more so, as the large general hospital. Many large hospital units built in recent years have turned into monuments to our medical tec.snology and are examples to many of how we shou'd treat our patients in this modern age. Unfortunately, the means of paying for these hospitals has not grown with our technology, and many of us now feel that we must question seriously the spiralling demands these units make on limited resources. Small community hospitals and peripheral services may well be completely overwhelmed and suffer accordingly. Small units which are effective and are supported by their communities in many tangible ways should be retained and, if possible, developed so that personal and continuing care can be provided in a way which patients wish and have long been used to. This in no way detracts from the essential usefulness of centres of excellence, which should be 